\title{
Comparison between mixed ceramic and reinforced ceramic tools in terms of cutting force components modelling and optimization when machining hardened steel AISI 4140 (60 HRC)
}

\author{
B. Fnides ${ }^{1,2, a}$, H. Aouici ${ }^{3}$, M. Elbah ${ }^{4}$, S. Boutabba ${ }^{2}$ And L. Boulanouar ${ }^{5}$ \\ 1 Département de Construction Mécanique et Productique (CMP), FGM\&GP, Université des Sciences et de la \\ Technologie Houari Boumediene (USTHB), BP 32 El-Alia, Bab-Ezzouar, 16111 Alger, Algérie \\ 2 Laboratoire Mécanique Appliquée des Nouveaux Matériaux (LMANM), Université 08 mai 1945-Guelma, BP 401, \\ 24000 Guelma, Algérie \\ 3 École Nationale Supérieure de Technologie (ENST) - ex CT siège DG. SNVI, R. N 5 Z.I. Rouiba, Alger, Algérie \\ 4 Laboratoire Mécanique et Structures (LMS), Université 08 mai 1945-Guelma, BP 401 Guelma, \\ 24000, Algérie \\ 5 LRTAPM, Université Badji-Moukhtar, BP 12, 23000 Annaba, Algérie
}

Received 23 June 2014, Accepted 17 Mai 2015

\begin{abstract}
This paper describes a comparison between mixed ceramic $\left[\mathrm{Al}_{2} \mathrm{O}_{3}(70 \%)+\mathrm{TiC}(30 \%)\right]$ and reinforced ceramic $\left[\mathrm{Al}_{2} \mathrm{O}_{3}(75 \%)+\mathrm{SiC}(25 \%)\right]$ tools in terms of cutting force components when machining in dry hard turning AISI 4140 steel, hardened to 60 HRC. The response surface methodology (RSM) and the analysis of variance (ANOVA) are applied to investigate effects of cutting speed, feed rate and depth of cut on cutting force components in order to model and optimize these technological parameters. Results of this study indicate that the machining with the mixed ceramic insert generates lower values of cutting force components than reinforced ceramic insert. Consequently, the mixed ceramic CC650 is the most powerful tool. The developed models can be used in the metal machining industries and would be helpful in selecting cutting variables for optimization of hard cutting process.
\end{abstract}

Key words: Ceramic / hard turning / AISI 4140 / cutting force / ANOVA / RSM

\section{Introduction}

Hard turning is a turning operation which is applied on high resistance alloy steels $(45<H R C<70)$ to obtain surface roughness values that are close to those obtained in grinding $(R a \approx 0.1 \mu \mathrm{m})$. The workpiece materials involved include various hardened alloy steels, tool steels, case-hardened steels, super alloys, nitride irons and hard-chrome-coated steels, and heat-treated powder metallurgical parts. Although this production method is a new subject, there are quite a few studies by several researchers in the literature. These studies mostly concern the turning of AISI 52100 bearing steel, H11-H13 hot work tool steel, and AISI 4130-4340 low alloy steel using CBN, ceramic, and coated carbide tools [1-4].

Alumina $\left(\mathrm{Al}_{2} \mathrm{O}_{3}\right)$ based ceramics are considered to be one of the most suitable tool materials for machining hardened steels because of their high hot hardness, wear resistance and chemical inertness. However, the ceramic tools possess a high degree of brittleness and low thermal shock resistance which may result in excessive

${ }^{a}$ Corresponding author: fbrahim@yahoo.fr chipping or fracture thereby reducing tool life. In order to improve their toughness, alumina $\left(\mathrm{Al}_{2} \mathrm{O}_{3}\right)$ based ceramics are usually reinforced with $\mathrm{TiC}, \mathrm{TiN}, \mathrm{Ti}(\mathrm{C}, \mathrm{N}), \mathrm{SiC}$, or $\mathrm{TiB}_{2}$ additions. Alumina reinforced with $\mathrm{SiC}$ whiskers is the toughest and most resistant to thermal shock of the $\mathrm{Al}_{2} \mathrm{O}_{3}$-based ceramics. This whisker reinforcement improves the notch resistance of the insert. The end result is a ceramic insert that can run at speeds five to six times that of conventional carbide insert in nickel-based materials. As an added benefit, the toughness of the $\mathrm{SiC}$ whiskers also makes this category of ceramic available for machining harder materials with interruptions [5].

The productivity in terms of volume chip carved of six cutting tools was investigated for two different cutting conditions in straight hard turning of X38CrMoV51 (50 HRC). The authors found that for the first cutting regime $\left(V c=120 \mathrm{~m} . \mathrm{min}^{-1}\right.$, ap $=0.15 \mathrm{~mm}$, and $\left.f=0.08 \mathrm{~mm} \cdot \mathrm{rev}^{-1}\right)$, the productivity of the uncoated cermets CT5015, the coated cermets GC1525, the uncoated carbide H13A, the reinforced ceramic CC670, the coated carbide GC3015 and the mixed ceramic CC650 are $2160 ; 1440 ; 6480 ; 11520 ; 23040$ and $70560 \mathrm{~mm}^{3}$, 
B. Fnides et al.: Mechanics \& Industry 16, 609 (2015)

Table 1. Factors affecting machinability and major investigators.

\begin{tabular}{|c|c|c|c|c|}
\hline Investigators & Major factors & Materials studied & Tools & Methodology \\
\hline C. Fetecau and F. Stan [15] & $\begin{array}{l}\text { cutting speed, feed } \\
\text { rate and side cutting } \\
\text { edge angle (SCEA) }\end{array}$ & $\begin{array}{l}\text { AISI1045 } \\
\text { steel }\end{array}$ & $\begin{array}{l}\text { Coated } \\
\text { carbide } \\
\text { insert }\end{array}$ & Taguchi method \\
\hline K. Bouacha et al. [16] & $\begin{array}{l}\text { cutting speed, feed } \\
\text { rate and depth of cut }\end{array}$ & $\begin{array}{l}\text { AISI } 52100 \\
\text { bearing steel }\end{array}$ & $\mathrm{CBN}$ & Response surface methodology \\
\hline R. Suresh et al. [17] & $\begin{array}{l}\text { cutting speed, } \\
\text { feed rate and depth of cut }\end{array}$ & $\begin{array}{l}\text { AISI } 4340 \\
\text { steel }\end{array}$ & $\begin{array}{l}\text { Coated } \\
\text { carbide } \\
\text { insert }\end{array}$ & Taguchi method and ANOVA \\
\hline M.W. Azizi et al. [18] & $\begin{array}{l}\text { cutting speed, feed } \\
\text { rate, depth of cut and } \\
\text { workpiece hardness }\end{array}$ & $\begin{array}{l}\text { AISI } 52100 \\
\quad \text { steel }\end{array}$ & $\begin{array}{l}\text { coated } \\
\text { mixed } \\
\text { ceramic }\end{array}$ & Taguchi method and ANOVA \\
\hline H. Aouici et al. [19] & $\begin{array}{l}\text { cutting speed, feed } \\
\text { rate and depth of cut }\end{array}$ & $\begin{array}{c}\text { AISI } \\
\text { H11steel }\end{array}$ & $\begin{array}{l}\text { CBN7020 } \\
\text { insert }\end{array}$ & Response surface methodology \\
\hline A.K. Sahoo and B. Sahoo [20] & $\begin{array}{l}\text { cutting speed, feed } \\
\text { rate, depth of cut and } \\
\text { machining time }\end{array}$ & $\begin{array}{l}\text { AISI } 4340 \\
\text { steel }\end{array}$ & $\begin{array}{l}\text { coated carbide } \\
\text { inserts }\end{array}$ & / \\
\hline M.H. Cetin et al. [21] & $\begin{array}{l}\text { cutting speed, feed } \\
\text { rate, depth of cut and } \\
\text { Type of cutting fluid }\end{array}$ & $\begin{array}{l}\text { AISI } 304 \mathrm{~L} \\
\text { steel }\end{array}$ & carbide insert & Taguchi method \\
\hline S.R. Das et al. [22] & $\begin{array}{l}\text { cutting speed, feed } \\
\text { rate and depth of cut }\end{array}$ & $\begin{array}{l}\text { AISI } 4140 \\
\text { steel }\end{array}$ & $\begin{array}{c}\text { coated } \\
\text { mixed ceramic }\end{array}$ & $\begin{array}{l}\text { Taguchi method, RSM } \\
\text { and ANOVA }\end{array}$ \\
\hline
\end{tabular}

respectively. The productivity of these three selected tools, i.e., mixed ceramic CC650, reinforced ceramic CC670, and coated carbide GC3015, for the second cutting regime $\left(f=0.08 \mathrm{~mm} \cdot \mathrm{rev}^{-1}\right.$, ap $=0.15 \mathrm{~mm}$ and $\left.V c=90 \mathrm{~m} \cdot \mathrm{min}^{-1}\right)$ are $85860 ; 12960$ and $30780 \mathrm{~mm}^{3}$, respectively. Their results prove that the mixed ceramic $\mathrm{Al}_{2} \mathrm{O}_{3}+\mathrm{TiC}$ (CC650) is more efficient than other tools used in terms of productivity [6].

The response surface methodology (RSM) is a family of statistical techniques for the design, empirical modelling and optimization of processes, where the responses of interest are influenced by several process variables (termed factors) $[7,8]$. RSM comprises the following three major components: (i) experimental design to determine the process factors' values based on which the experiments are conducted and data are collected; (ii) empirical modelling to approximate the relationship (i.e. the response surface) between responses and factor; (iii) optimization to find the best response value based on the empirical model. In addition, the above three stage procedure is typically operated in an iterative manner, where the information attained from previous iterations is utilized to guide the search for better response variables.

Dureja et al. applied the response surface methodology (RSM) to investigate the effect of cutting parameters on flank wear and surface roughness in hard turning of AISI H11 steel with a coated-mixed ceramic tool. The study indicated that the flank wear is influenced principally by feed rate, depth of cut and workpiece hardness [9]. Neseli et al. [10] applied response surface methodology (RSM) to optimize the effect of tool geometry parameters on surface roughness in hard turning of AISI 1040 with P25 tool. Aouici et al. [11] applied response surface methodology (RSM) to investigate the effect of cutting parameters on surface roughness in hard turning of AISI H11 with CBN tool. Recently, Aouici et al. [7] have applied response surface methodology (RSM) to optimize the effect of cutting parameters at the different levels of hardness workpiece on surface roughness in the case of the hard turning of AISI H11 with CBN tool. Elbah et al. [12] applied response surface methodology (RSM) and ANOVA to investigate the machinability of hardened AISI 4140 cold work tool steel using a range of cutting tools. The results indicated that surface roughness of 4140 steel was improved as cutting speed was elevated and deteriorated with feed rate. However, the surface quality obtained with the wiper ceramic insert allowed a surface finish as good when compared with conventional ceramic insert is 2.5. Lalwani et al. [13] studied the effect of cutting parameters in turning on cutting forces and surface roughness. To this end, a number of experiments based on RSM have been carried out and linear and quadratic models have been formed to explain the relation between the parameters.

Lima et al. [14] published the results of an investigation concerning the effect of cutting speed, feed rate and depth of cut on cutting forces in hardened AISI 4340 high strength low alloy steel and AISI D2 cold work tool steel materials.

Cutting force components influence the deformation of the machined workpiece, its dimensional accuracy, the formation of chip and the tool nose. Previously published studies show the tendency to seek effect of cutting conditions (like cutting speed, feed rate and depth of cut) on cutting force components (Tab. 1).

\section{Experimental procedure}

Turning experiments were performed in dry conditions using an universal lathe type SN 40C with $6.6 \mathrm{~kW}$ spindle 


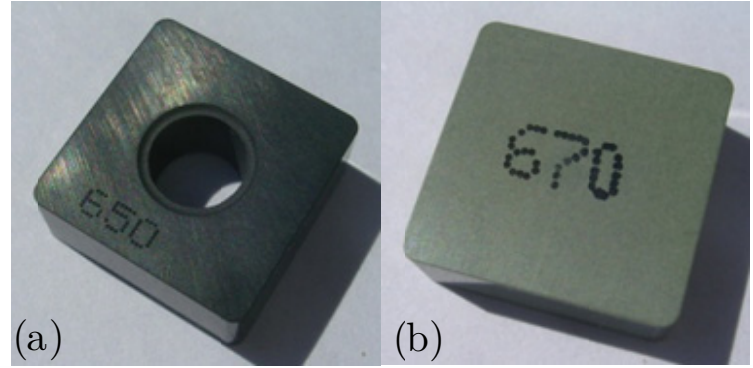

Fig. 1. Ceramic cutting tools: (a) CC650 and (b) CC670.

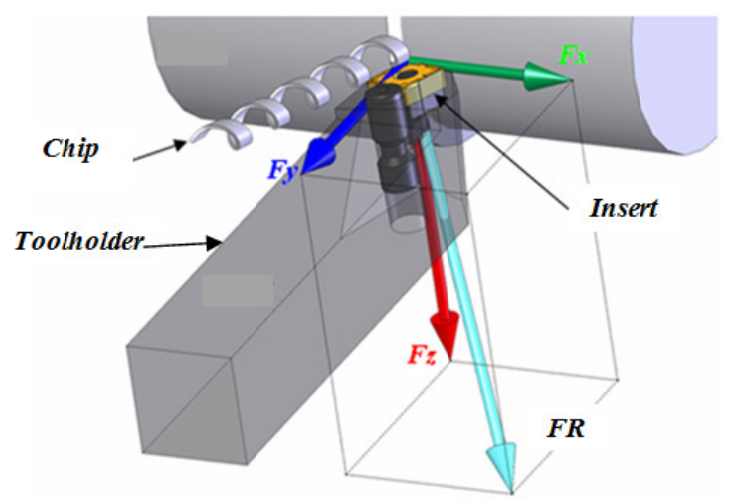

Fig. 2. Components of cutting force.

power. The workpiece material was AISI 4140 steel with an initial grain size of about $120 \mu \mathrm{m}$, used as the samples for hot compression; torsion test and ability for polishing enable it to answer the most severe requests in spindles, logging parts and pump shafts. It is hardened to $60 \mathrm{HRC}$. Its hardness was measured by a digital durometer DM2D. Its chemical composition (in wt.\%) is given as: C 0.43; $\mathrm{Cr}$ 1.10; Mo 0.19; V 0.005; Si 0.24; Mn 0.79; S 0.024; Ni 0.022 ; Fe 96.315 and other components 0.884 . The inserts used were mixed ceramic CC650 and reinforced ceramic CC670, removable, of square form with eight cutting edges and having designation SNGA 120408 T01020 and SNGN 120408T01020, respectively (Fig. 1). Its nose radius is $r_{\varepsilon}=0.8 \mathrm{~mm}$. These inserts were mounted on commercial toolholders of designation PSBNR2525M12 and CSBNR2525M12 with the geometry of active part characterized by the following angles:major cutting edge angle $\chi=75^{\circ}$; clearance angle $\alpha=6^{\circ}$; rake angle $\gamma=-6^{\circ}$; inclination angle $\lambda=-6^{\circ}$. Short duration tests were performed (machining length is $18 \mathrm{~mm}$ ). Each test is realized three times with a new cutting edge. In order to carry out this experimental study, these measurements were repeated three times and the considered result is an average of the three values given by the three trials.

The three components of the cutting force; feed force or axial force $(F x: F a)$, thrust force or radial force $(F y: F r)$ and tangential force $(F z: F t)$, schematically shown in Figure 2, were measured in real time with a Kistler three component dynamometer model 9257 B linked via a multichannel charge amplifier (type 5011 B) to high impedance cable.Before each test this dynamometer is reset for calibration.
Table 2. Cutting parameters and their levels for turning.

\begin{tabular}{|c|c|c|c|c|}
\hline \multirow{2}{*}{ Symbol } & \multirow{2}{*}{ Control factor } & \multirow{2}{*}{ Unit } & \multicolumn{2}{|c|}{ Levels } \\
\hline & & & Level 1 & Level 2 \\
\hline$V c$ & Cutting speed & $\mathrm{m} \cdot \min ^{-1}$ & 90 & 180 \\
\hline$f$ & Feed rate & mm.rev ${ }^{-1}$ & 0.08 & 0.16 \\
\hline$a p$ & Depth of cut & $\mathrm{mm}$ & 0.25 & 0.50 \\
\hline
\end{tabular}

Since there are a large number of variables controlling the cutting process, some mathematical models are required to represent this process. However, these models have to be developed using only the significant parameters influencing the process rather than including all the parameters.

In order to achieve this, statistical analysis of the experimental results will have to be processed using the analysis of variance (ANOVA). The latter is a computational technique that enables the estimation of the relative contributions of each of the control factors to the overall measured response. In this work, only the significant parameters will be used to develop mathematical models using response surface methodology (RSM). RSM is a collection of mathematical and statistical techniques that are useful for the modeling and analysis of problems in which response of interest is influenced by several variables and the objective is to optimize the response $[7,8]$.

Two levels were defined for each cutting variable as given in Table 2. The variable levels were chosen within the intervals recommended by the cutting tool manufacturer. Three cutting variables at two levels led to a total of 8 tests.

\section{Results and discussion}

\subsection{Evolution of the cutting force components}

\subsubsection{Influence of the cutting parameters on the feed force (axial force Fx:Fa)}

It can be seen in Figure 3 that all components of the feed force (axial force $F a$ ) increased as the feed rate was increased, for both ceramic tools CC650 and CC670. For the reason that as the feed rate increases, the chip cross-sectional area increases. In this case, more plastic deformation energy is required for chip formation which leads to increase in main cutting force. However, the insert CC650 provides lower values than the CC670 ceramic tool. As seen in Figure 3, both mixed and reinforced cutting tools have approximately the same grades. The ratio of $F a_{\mathrm{CC} 670} / F a_{\mathrm{CC} 650}$ is 1.06 for a cutting speed of $180 \mathrm{~m} \cdot \mathrm{min}^{-1}$ whereas it is about 1.3 for a cutting speed of $90 \mathrm{~m} \cdot \mathrm{min}^{-1}$.

\subsubsection{Influence of the cutting parameters on the thrust force (radial force Fy:Fr)}

In Figure 4 the evolution of the thrust force (radial force $F r$ ) with the feed rate for several depths of cut values and several cutting speeds values is shown for both 


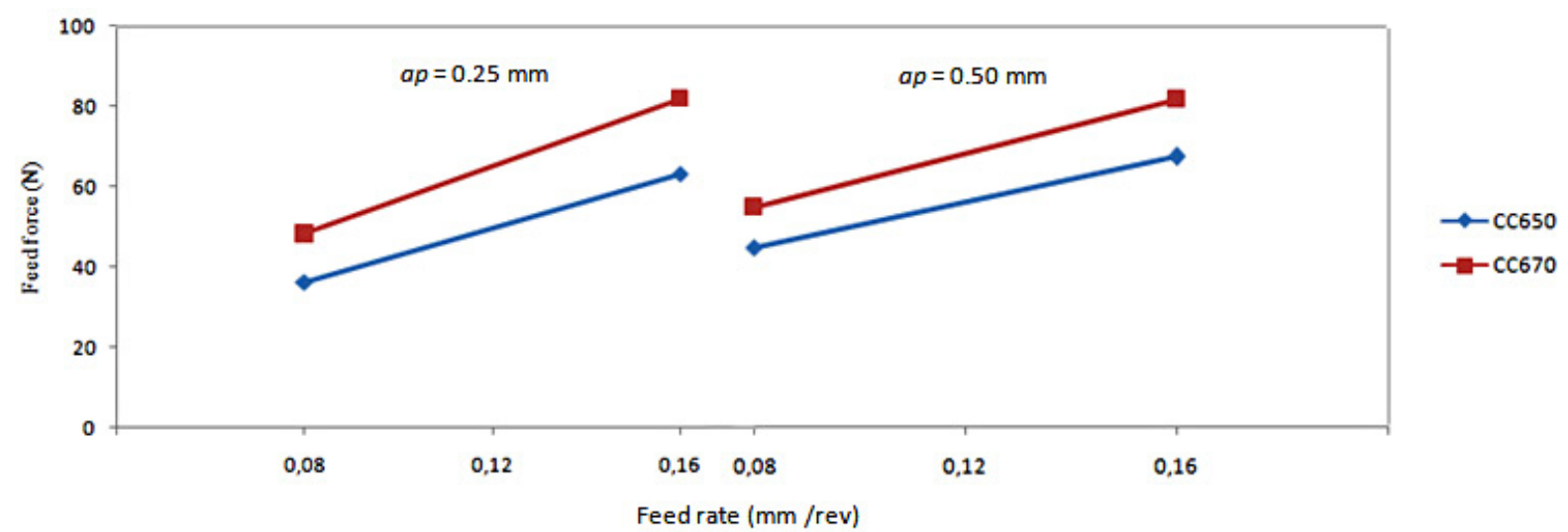

(a)

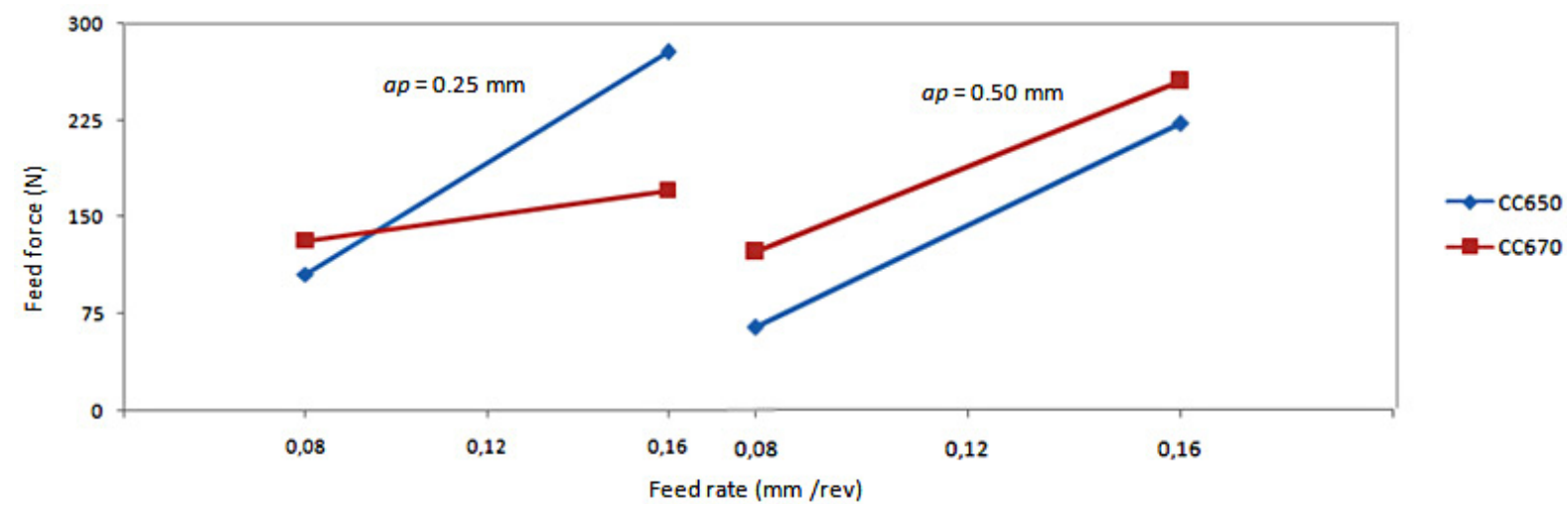

(b)

Fig. 3. Effect of feed rate on feed force at various depths of cut (CC650 and CC670). (a) $V c=90 \mathrm{~m} \cdot \mathrm{min}^{-1}$. (b) $V c=$ $180 \mathrm{~m} \cdot \mathrm{min}^{-1}$.

ceramic tools CC650 and CC670. Increasing the cutting parameters increases the thrust force and the depth of cut seems to be the most influential parameter. This can be attributed to the increase in chip cross-sectional area with increasing depth of cut, as mentioned by Aouici et al. [7] and proved by Bouacha et al. [16]. In general the CC650 tool gives lower values than CC670.In fact, an increase of depth of cut from 0.25 to $0.50 \mathrm{~mm}$ causes a drop mean of the tow thrust forces $\left(F r_{\mathrm{CC} 650}\right.$ and $\left.F r_{\mathrm{rCC} 670}\right)$ at $83.3 \%$ and 54\% for CC650 and CC670 tools, respectively.

\subsubsection{Influence of the cutting parameters on the tangential force (Fz:Ft)}

Figure 5 shows the evolution of the tangential force $F t$ as a function of the feed rate, for several depths of cut and several cutting speeds values for both ceramic tools CC650 and CC670. According to the graph, it can be seen that $F t$ increases with feed rate and mostly with depth of cut. The evolution of $F t$ with cutting speed is not clear for this range of cutting conditions. In general, the lower cutting forces were registered at the higher cutting speeds. This can be related to the temperature increase in cutting zone and leads to the drop of the workpiece yield strength and chip thickness. These results are similar to those mentioned by the authors $[23,24]$.

\subsection{Response surface methodology (RSM)}

RSM is a statistical technique based on simple multiple regressions. With this technique, the effect of two or more factors on quality criteria can be investigated and optimum values are obtained [7]. In RSM design, there should be at least two levels for each factor. In this way, the factor values that are not actually tested using fewer experimental combinations and the combinations themselves can be estimated $[25,26]$.

Table 3 presents experimental results of cutting force components ( $F x, F y$ and $F z$ ) for various combinations of cutting regime parameters (cutting speed, feed rate and depth of cut) according to $2^{3}(8)$ full factorial design.

The results of analysis of variance for cutting force components $(F x, F y$ and $F z$ ) are shown in Tables 4-6. These tables also show the degrees of freedom (DF), sum of squares (SS), mean square (MS), F-values (F-value) and probability (Prob.) of each factor and different interactions. A low P-value indicates statistical significance for the source on the corresponding response.

Table 4 shows the results of analysis of variance (ANOVA) for feed force of CC650 and CC670 tools. This analysis was carried out for a 5 per cent significance level, i.e. for a 95 per cent confidence level. The last column of the table shows the percentage of each factor contribution (Cont.\%) on the total variation, thus indicating the 

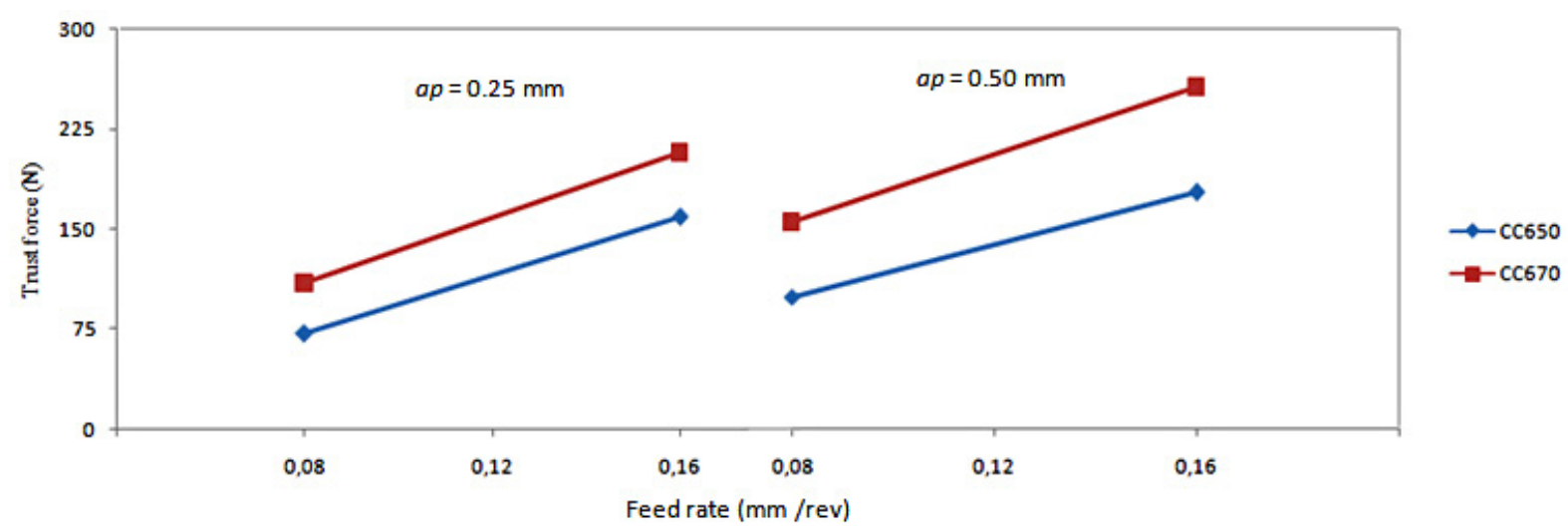

(a)

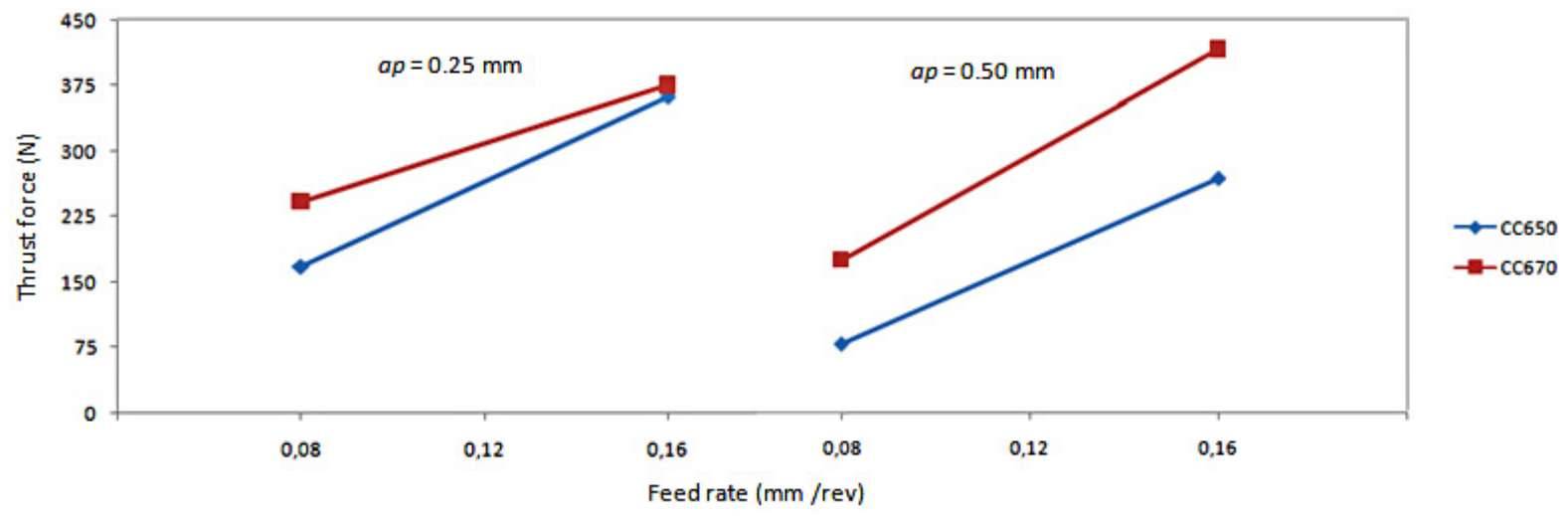

(b)

Fig. 4. Effect of feed rate on thrust force at various depths of cut (CC650 and CC670). (a) $V c=90 \mathrm{~m} \cdot \mathrm{min}^{-1}$. (b) $V c=$ $180 \mathrm{~m} \cdot \mathrm{min}^{-1}$.

Table 3. Experimental results for cutting force components.

\begin{tabular}{|c|c|c|c|c|c|c|c|c|c|}
\hline \multirow{3}{*}{ Test $\mathrm{N}^{\circ}$} & \multirow{2}{*}{\multicolumn{3}{|c|}{ Machining parameters }} & \multicolumn{6}{|c|}{ Response factors } \\
\hline & & & & & CC650 & & & CC670 & \\
\hline & $V c\left(\mathrm{~m}_{\mathrm{min}} \mathrm{mi}^{-1}\right)$ & $f\left(\mathrm{~mm}^{\prime} \cdot \mathrm{rev}^{-1}\right)$ & $a p(\mathrm{~mm})$ & $F x(\mathrm{~N})$ & $F y(\mathrm{~N})$ & $F z(\mathrm{~N})$ & $F x(\mathrm{~N})$ & $F y(\mathrm{~N})$ & $F z(\mathrm{~N})$ \\
\hline 1 & 90 & 0.08 & 0.25 & 36.17 & 71.63 & 88.90 & 48.23 & 109.53 & 98.83 \\
\hline 2 & 90 & 0.08 & 0.50 & 42.87 & 98.50 & 92.33 & 52.40 & 153.63 & 95.14 \\
\hline 3 & 90 & 0.16 & 0.25 & 63.19 & 158.93 & 154.90 & 82.07 & 207.23 & 177.14 \\
\hline 4 & 90 & 0.16 & 0.50 & 64.24 & 175.68 & 146.40 & 78.09 & 254.10 & 146.81 \\
\hline 5 & 180 & 0.08 & 0.25 & 105.48 & 167.84 & 178.67 & 131.50 & 242.70 & 199.88 \\
\hline 6 & 180 & 0.08 & 0.50 & 58.87 & 82.57 & 141.82 & 112.39 & 182.35 & 158.40 \\
\hline 7 & 180 & 0.16 & 0.25 & 277.69 & 363.19 & 338.01 & 171.10 & 375.69 & 304.01 \\
\hline 8 & 180 & 0.16 & 0.50 & 202.99 & 279.21 & 270.44 & 232.86 & 432.04 & 314.98 \\
\hline
\end{tabular}

degree of influence on the result. From Table 4, it can be seen that the cutting speed (41.09 and 69.02$) \%$ and feed rate (31.09 and 22.22$) \%$ have the major statistical significance as regards feed force Fx of CC650 and CC670 respectively. The depth of cut (3.01 and 0.85$) \%$ does not present a statistically significant effect on $F x$.

The other important coefficient $R^{2}$ in the resulting ANOVA table is defined as the ratio of the explained variation to the total variation and is a measure of the degree of fit. When $R^{2}$ approaches to unity, the better response model fits the actual data. The values of $R^{2}$ calculated in Table 3 for these models are over 0.95 and reasonably close to unity, which are acceptable. It denotes that about $95 \%$ of the variability in the data is explained by these models. It also confirms that these models provide an excellent explanation of the relationship between the independent factors and the response.

From Table 5, feed rate had the main statistical influence on thrust force Fy (54.02 and 51.07)\% for CC650 and CC670 tools, respectively. The next largest factor influencing on Fy is cutting speed with (26.27 and 39.11)\% contribution. The depth of cut with (2.75 and 1.14$) \%$ contribution, has a very weak significance effect.

The $R^{2}$ value is high, close to 1 , which is desirable. The "R-Squared" of (0.9998 and 0.9807$)$ are in reasonable agreement with the "Adj $R$-Squared" of (0.9984 and 


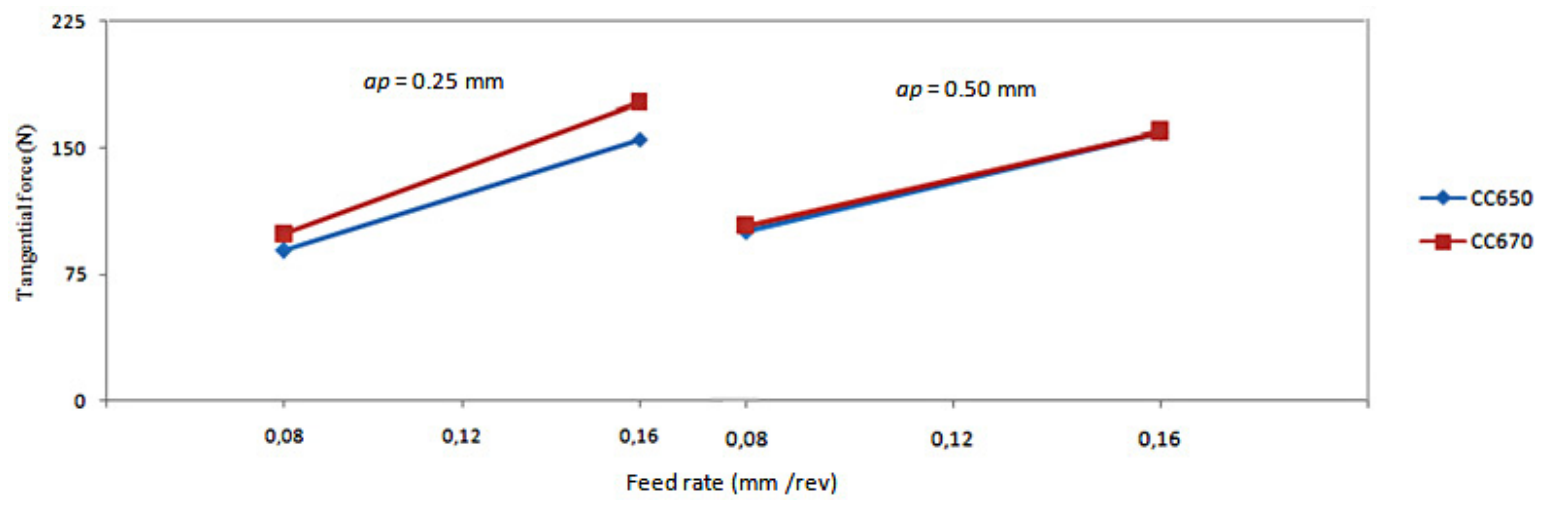

(a)

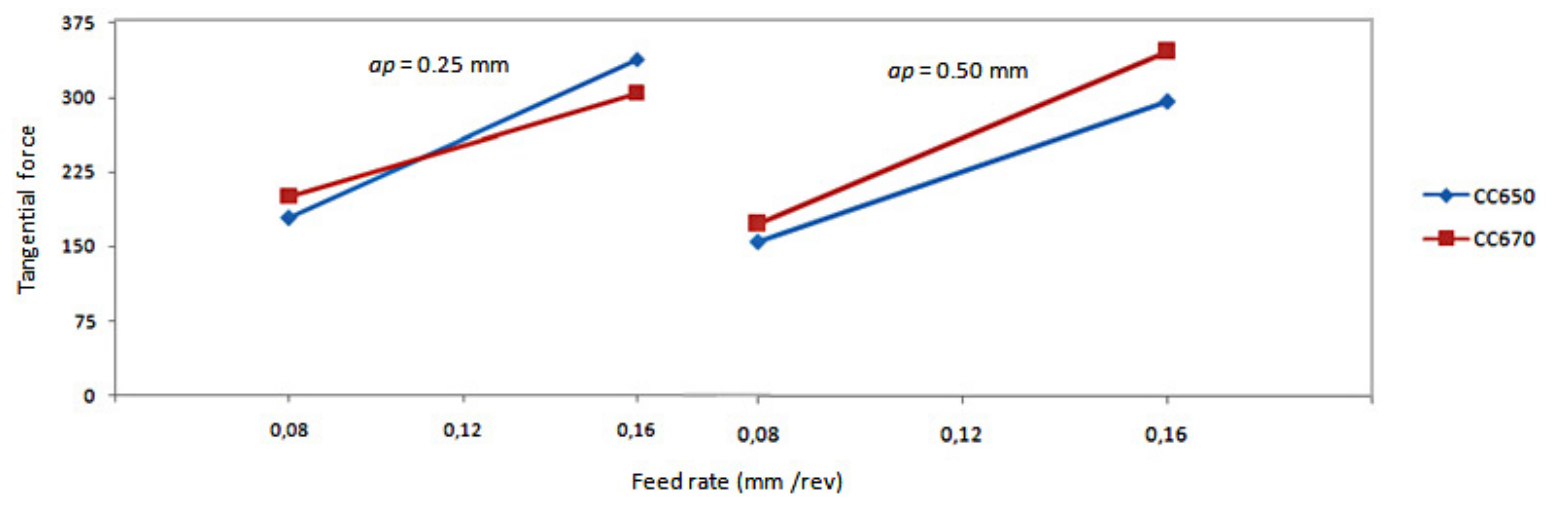

(b)

Fig. 5. Effect of feed rate on tangential force at various depths of cut (CC650 and CC670). (a) $V c=90 \mathrm{~m} \cdot \mathrm{min}^{-1}$. (b) $V c=$ $180 \mathrm{~m} \cdot \mathrm{min}^{-1}$.

0.8651) for CC650 and CC670 tools, respectively. The adjusted $R^{2}$ value is particularly useful when comparing models with different number of terms. "Adequate Precision" measures the signal to noise ratio. A ratio greater than 4 is desirable. Our ratio of (77.265 and 7.804) for CC650 and CC670 tools respectively, indicates an adequate signal. So, these models can be used to navigate the design space.

According to Table 6 , it can be seen that the cutting speed (47.72 and 54.72$) \%$ followed by feed rate (39.86 and $39.58) \%$ had the greatest influence on $F z$ for both cutting tools (CC650 and CC670), respectively. The depth of cut (2.87 and 1.08)\% factor shows little statistical significance with respect to $F z$. Similarly, the interactions $(V c \times f)$, $(V c \times a p)$ and $f \times a p)$ are not significant. Respectively, their contributions are (6.75 and $4.43 ;(2.36$ and 0.003$)$ and (0.44 and 0.17$) \%$.

The $R^{2}$ value is high, close to 1 , which is desirable. The " $R$-Squared" of $(0.9992$ and 0.9840$)$ are in reasonable agreement with the "Adj $R$-Squared" of (0.9941 and 0.8883) for CC650 and CC670 tools, respectively. The adjusted $R^{2}$ value is particularly useful when comparing models with different number of terms. "Adequate Precision" measures the signal to noise ratio. A ratio greater than 4 is desirable. Our ratio of (40.087 and 8.741) for
CC650 and CC670 tools respectively, indicates an adequate signal. So, these models can be used to navigate the design space.

\section{Regression equations}

The relationship between the factors and the performance measures were modeled by polynomial regression. The regression equations obtained were as follows.

The feed force $\left(F x_{\mathrm{CC} 650}\right)$ model is given below in Equation (1). Its coefficient of determination $\left(R^{2}\right)$ is $99.88 \%$.

$$
\begin{aligned}
F x_{\mathrm{CC} 650}= & -33.925+0.061 V c-1055.875 f+374.84 a p \\
& +18.607 V c \times f-2.868 V c \times a p-843.5 f \times a p
\end{aligned}
$$

The feed force $\left(F x_{\mathrm{CC} 670}\right)$ model is given below in Equation (2). Its coefficient of determination $\left(R^{2}\right)$ is $96.48 \%$.

$$
\begin{aligned}
F x_{\mathrm{CC} 670}= & -112.702-0.116 V c-938.062 f-302.7 a p \\
& +6.982 V c \times f+0.943 V c \times a p+1818 f \times a p
\end{aligned}
$$


Table 4. Analysis of variance for $F x$.

\begin{tabular}{|c|c|c|c|c|c|c|}
\hline Source & SS & $\mathrm{DF}$ & $\mathrm{MS}$ & $F$-value & Prob. & Cont. $\%$ \\
\hline \multicolumn{7}{|c|}{ (a) CC650 } \\
\hline Model & 53479.7676 & 6 & 8913.29459 & 141.606289 & 0.0642 & \\
\hline$V c$ & 24041.8592 & 1 & 24041.8592 & 381.955116 & 0.0325 & 44.96 \\
\hline$f$ & 16627.5848 & 1 & 16627.5848 & 264.163891 & 0.0391 & 31.09 \\
\hline$a p$ & 1611.9842 & 1 & 1611.9842 & 25.6097337 & 0.1242 & 3.01 \\
\hline$V c \times f$ & 8973.98045 & 1 & 8973.98045 & 142.570411 & 0.0532 & 16.78 \\
\hline$V c \times a p$ & 2082.06045 & 1 & 2082.06045 & 33.0778761 & 0.1096 & 3.89 \\
\hline$f \times a p$ & 142.29845 & 1 & 142.29845 & 2.2607079 & 0.3736 & 0.27 \\
\hline Error & 62.9442 & 1 & 62.9442 & & & \\
\hline Total & 53542.7118 & 7 & & & & 100 \\
\hline \multicolumn{4}{|c|}{$\mathrm{SD}=7.93$} & \multicolumn{3}{|l|}{$R^{2}=0.9988$} \\
\hline \multicolumn{4}{|c|}{ Mean $=106.44$} & \multicolumn{3}{|c|}{$R^{2}$ Adjusted $=0.9918$} \\
\hline \multicolumn{4}{|c|}{ Coefficient of variation $=7.45$} & \multicolumn{3}{|c|}{$R^{2}$ Predicted $=0.9248$} \\
\hline \multicolumn{4}{|c|}{ Predicted residual error of sum of squares (PRESS) $=4028.43$} & \multicolumn{3}{|c|}{ Adequate precision $=32.544$} \\
\hline \multicolumn{7}{|c|}{ (b) CC670 } \\
\hline Model & 27134.2764 & 6 & 4522.37939 & 4.56543118 & 0.3437 & \\
\hline$V c$ & 18726.9305 & 1 & 18726.9305 & 18.9052056 & 0.1439 & 69.02 \\
\hline$f$ & 6028.02 & 1 & 6028.02 & 6.08540507 & 0.2452 & 22.22 \\
\hline$a p$ & 229.4082 & 1 & 229.4082 & 0.2315921 & 0.7145 & 0.85 \\
\hline$V c \times f$ & 1263.53645 & 1 & 1263.53645 & 1.27556496 & 0.4614 & 4.66 \\
\hline$V c \times a p$ & 225.35645 & 1 & 225.35645 & 0.22750178 & 0.7167 & 0.83 \\
\hline$f \times a p$ & 661.0248 & 1 & 661.0248 & 0.66731757 & 0.5639 & 2.44 \\
\hline Error & 990.57005 & 1 & 990.57005 & & & \\
\hline Total & 28124.8464 & 7 & & & & 100 \\
\hline \multicolumn{4}{|c|}{$\mathrm{SD}=31.47$} & \multicolumn{3}{|l|}{$R^{2}=0.9648$} \\
\hline \multicolumn{4}{|c|}{ Mean $=113.58$} & \multicolumn{3}{|c|}{$R^{2}$ Adjusted $=0.7535$} \\
\hline \multicolumn{4}{|c|}{ Coefficient of variation $=27.71$} & \multicolumn{3}{|c|}{$R^{2}$ Predicted $=-1.2541$} \\
\hline \multicolumn{4}{|c|}{ Predicted residual error of sum of squares (PRESS) $=63369.84$} & \multicolumn{3}{|c|}{ Adequate precision $=6.31$} \\
\hline
\end{tabular}

The thrust force $\left(F y_{\mathrm{CC} 650}\right)$ model is given below in Equation (3). Its coefficient of determination $\left(R^{2}\right)$ is $99.98 \%$.

$$
\begin{aligned}
F y_{\mathrm{CC} 650}= & -125.861+0.955 V c-311.156 f+539.47 a p \\
& +15.799 V c \times f-4.730 V c \times a p-220.75 f \times a p
\end{aligned}
$$

The thrust force $\left(F y_{\mathrm{CC} 670}\right)$ model is given by the following Equation (4) with a determination coefficient $\left(R^{2}\right)$ of $98.07 \%$.

$$
\begin{aligned}
F y_{\mathrm{CC} 670}= & 38.753+0.665 V c-1034.656 f+13.47 a p \\
& +12.813 V c \times f-2.11 V c \times a p+2986.75 f \times a p
\end{aligned}
$$

The tangential force $\left(F z_{\mathrm{CC} 650}\right)$ is given by Equation (5) with a determination coefficient $\left(R^{2}\right)$ of $99.92 \%$.

$$
\begin{aligned}
F z_{\mathrm{CC} 650}= & -73.796+0.668 V c+100.968 f+316.51 a p \\
& +11.659 V c \times f-2.207 V c \times a p-1066.25 f \times a p
\end{aligned}
$$

The tangential force $\left(F z_{\mathrm{CC} 670}\right)$ is given by Equation (6) with a determination coefficient $\left(R^{2}\right)$ of $98.40 \%$.

$$
\begin{aligned}
F z_{C C 670}= & 72.388+0.157 V c-246.656 f-152.49 a p \\
& +9.078 V c \times f+0.078 V c \times a p+645.25 f \times a p
\end{aligned}
$$

\section{Responses surface analysis}

Figure 6a presents the influences of cutting speed $(V c)$ and feed rate $(f)$ on the cutting force components (Fa:Fx, Fr:Fy and Ft:Fz) for both ceramic tools CC650 and CC670, while the depth of cut $(a p)$ is kept at the middle level. The effects of the cutting speed $(V c)$ and depth of cut $(a p)$ on the cutting force components for both ceramic tools CC650 and CC670 are shown in Figure 6b, while the feed rate $(f)$ is kept at the middle level. Figure $6 \mathrm{c}$ shows the estimated response surface in relation to the feed rate $(f)$ and depth of cut $(a p)$, while cutting speed $(V c)$ is kept at the middle level. Mixed ceramic cutting tool CC650 has the lower values compared with reinforced ceramic cutting tools CC670, in particular the feed force.

In general, the insert CC650 generates lower values of cutting force components than the CC670 ceramic reinforced tool. For example: $F x_{\mathrm{CC} 670} \approx 1.07 F x_{\mathrm{CC} 650}$, $F y_{\mathrm{CC} 670} \approx 1.4 F y_{\mathrm{CC} 650}$ and $F z_{\mathrm{CC} 670} \approx 1.05 F z_{\mathrm{CC} 650}$. This is due to the chemical composition of CC650 insert (percentage of $\mathrm{TiC}$ ). TiC guarantees low thermal conductivity, toughness and ensures high chemical inertness. The properties of $\mathrm{TiC}$ slow triggering process of the different mechanisms of wear.

Figure 7 shows the comparison between the values of the cutting force components (Fa:Fx, Fr:Fy and Ft:Fz) for both ceramic tools CC650 and CC670. 
B. Fnides et al.: Mechanics \& Industry 16, 609 (2015)

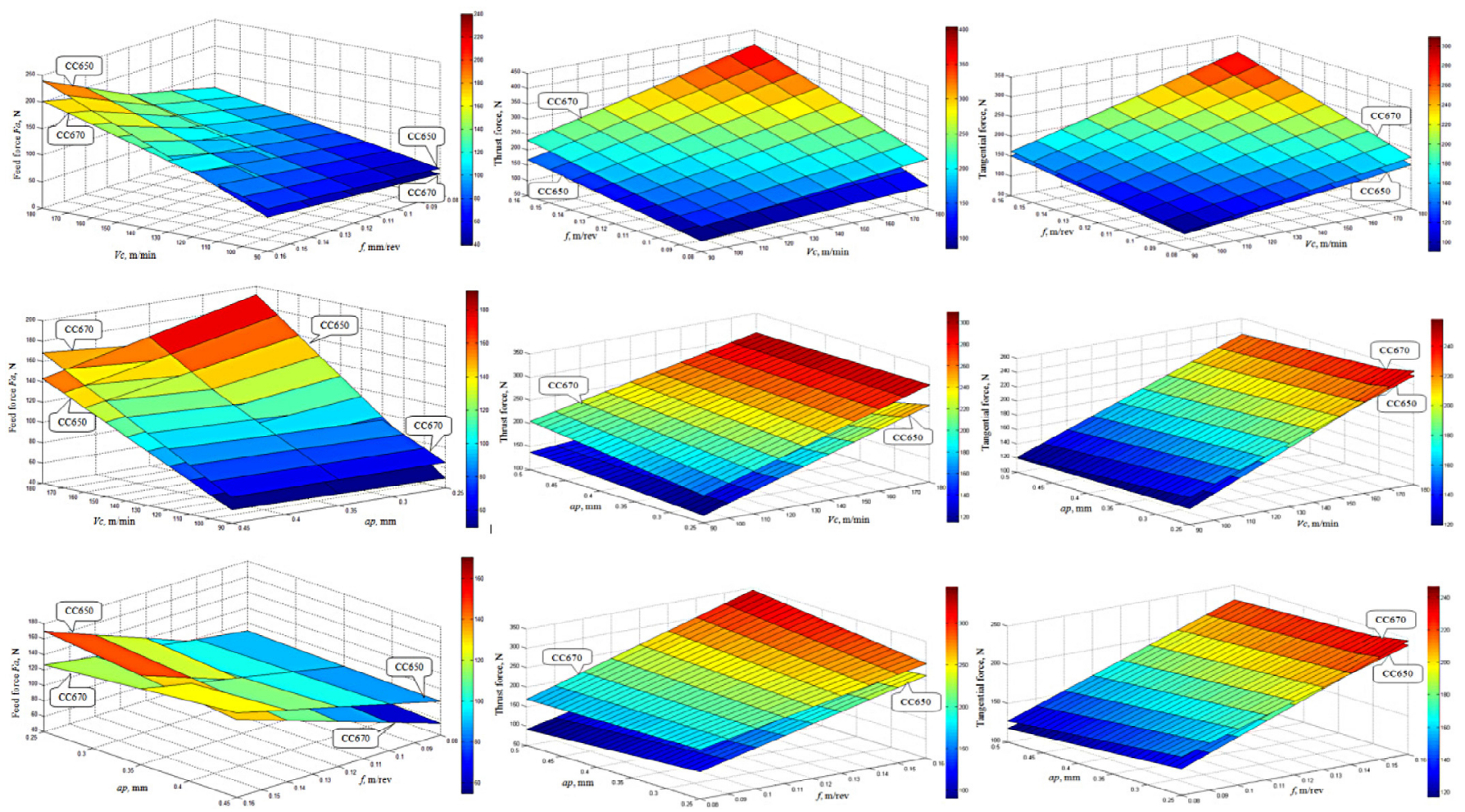

Fig. 6. Comparison of response surface for cutting force components versus $V c, f$ and $a p$.

Table 5. Analysis of variance for Fy.

\begin{tabular}{|c|c|c|c|c|c|c|}
\hline Source & $\overline{S S}$ & $\overline{\mathrm{DF}}$ & $\mathrm{MS}$ & $F$-value & Prob. & Cont. $\%$ \\
\hline \multicolumn{7}{|c|}{ (a) CC650 } \\
\hline Model & 71649.0611 & 6 & 11941.5102 & 733.800412 & 0.0283 & \\
\hline$V c$ & 18824.7906 & 1 & 18824.7906 & 1156.77489 & 0.0187 & 26.27 \\
\hline$f$ & 38707.3576 & 1 & 38707.3576 & 2378.54966 & 0.0131 & 54.02 \\
\hline$a p$ & 1972.86211 & 1 & 1972.86211 & 121.231487 & 0.0577 & 2.75 \\
\hline$V c \times f$ & 6470.10001 & 1 & 6470.10001 & 397.584726 & 0.0319 & 9.03 \\
\hline$V c \times a p$ & 5664.20461 & 1 & 5664.20461 & 348.062818 & 0.0341 & 7.91 \\
\hline$f \times a p$ & 9.7461125 & 1 & 9.7461125 & 0.59889422 & 0.5807 & 0.01 \\
\hline Error & 16.2735125 & 1 & 16.2735125 & & & \\
\hline Total & 71665.3346 & 7 & & & & 100 \\
\hline \multicolumn{4}{|c|}{$\mathrm{SD}=4.03$} & \multicolumn{3}{|l|}{$R^{2}=0.9998$} \\
\hline \multicolumn{4}{|c|}{ Mean $=174.69$} & \multicolumn{3}{|c|}{$R^{2}$ Adjusted $=0.9984$} \\
\hline \multicolumn{4}{|c|}{ Coefficient of variation $=2.31$} & \multicolumn{3}{|c|}{$R^{2}$ Predicted $=0.9855$} \\
\hline \multicolumn{4}{|c|}{ Predicted residual error of sum of squares (PRESS) $=1041.50$} & \multicolumn{3}{|c|}{ Adequate precision $=77.265$} \\
\hline \multicolumn{7}{|c|}{ (b) CC670 } \\
\hline Model & 82580.6937 & 6 & 13763.4489 & 8.48283595 & 0.2569 & \\
\hline$V c$ & 32294.8405 & 1 & 32294.8405 & 19.9043013 & 0.1404 & 39.11 \\
\hline$f$ & 42173.3403 & 1 & 42173.3403 & 25.9927238 & 0.1233 & 51.07 \\
\hline$a p$ & 945.472613 & 1 & 945.472613 & 0.58272379 & 0.5849 & 1.14 \\
\hline$\overline{V c \times f}$ & 4255.49251 & 1 & 4255.49251 & 2.62279063 & 0.3522 & 5.15 \\
\hline$V c \times a p$ & 1127.41261 & 1 & 1127.41261 & 0.69485899 & 0.5576 & 1.37 \\
\hline$f \times a p$ & 1784.13511 & 1 & 1784.13511 & 1.09961722 & 0.4849 & 2.16 \\
\hline Error & 1622.50561 & 1 & 1622.50561 & & & \\
\hline Total & 84203.1993 & 7 & & & & 100 \\
\hline \multicolumn{4}{|c|}{$\mathrm{SD}=40.28$} & \multicolumn{3}{|l|}{$R^{2}=0.9807$} \\
\hline \multicolumn{4}{|c|}{ Mean $=234.66$} & \multicolumn{3}{|c|}{$R^{2}$ Adjusted $=0.8651$} \\
\hline \multicolumn{4}{|c|}{ Coefficient of variation $=16.46$} & \multicolumn{3}{|c|}{$R^{2}$ Predicted $=-02332$} \\
\hline \multicolumn{4}{|c|}{ Predicted residual error of sum of squares (PRESS) $=1.03 \mathrm{E}+5$} & \multicolumn{3}{|c|}{ Adequate precision $=7.804$} \\
\hline
\end{tabular}


B. Fnides et al.: Mechanics \& Industry 16, 609 (2015)

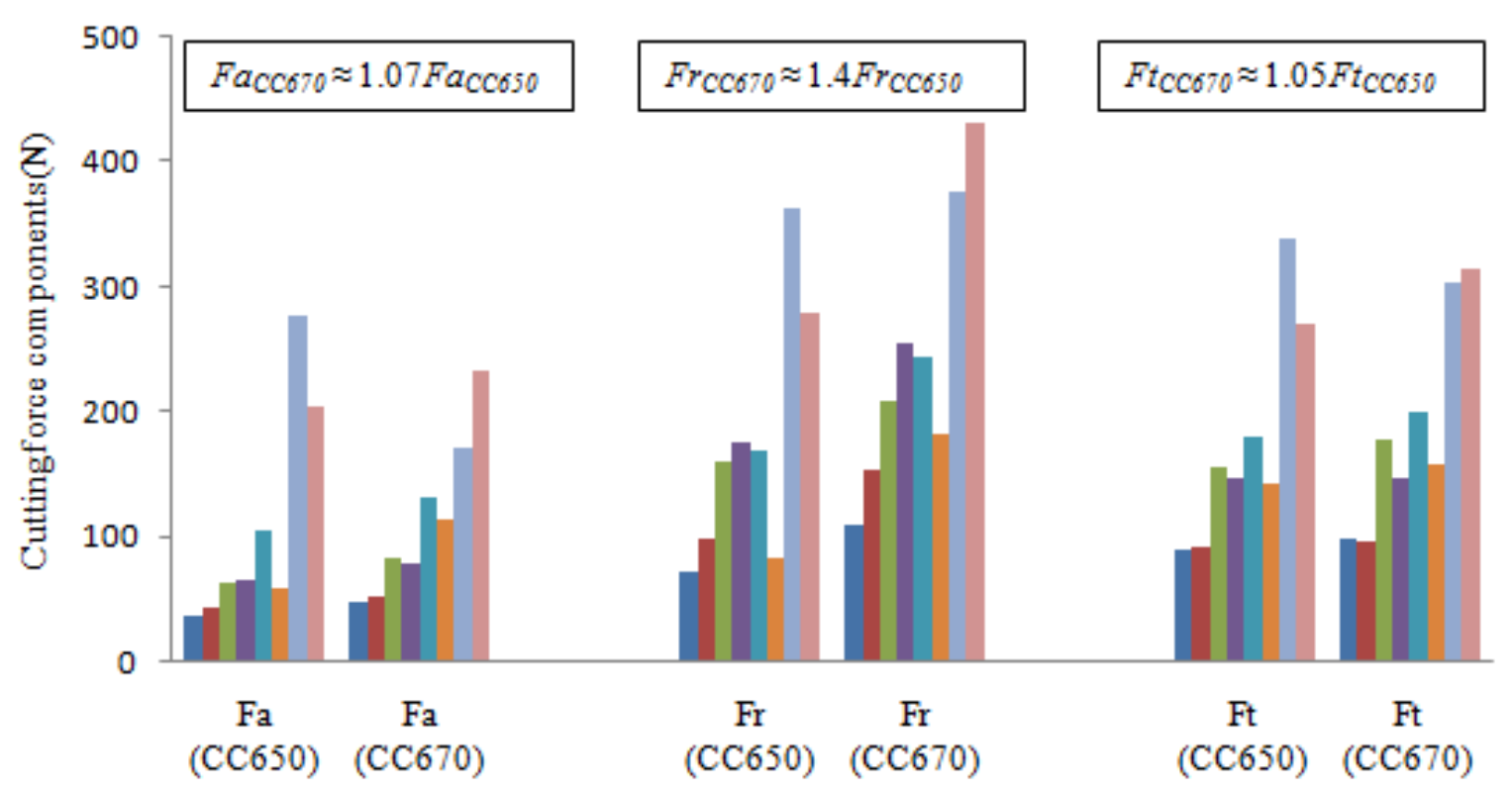

Experimentalrun order

Fig. 7. Comparison between CC650 and CC670 for cutting force components.

Table 6. Analysis of variance for $F z$.

\begin{tabular}{|c|c|c|c|c|c|c|}
\hline Source & SS & $\mathrm{DF}$ & MS & F-value & Prob. & Cont. \% \\
\hline \multicolumn{7}{|c|}{ (a) CC650 } \\
\hline Model & 52204.3658 & 6 & 8700.72763 & 197.14783 & 0.0545 & \\
\hline$V c$ & 24910.236 & 1 & 24910.236 & 564.435433 & 0.0268 & 47.72 \\
\hline$f$ & 20811.0601 & 1 & 20811.0601 & 471.553128 & 0.0293 & 39.86 \\
\hline$a p$ & 1498.50751 & 1 & 1498.50751 & 33.9543446 & 0.1082 & 2.87 \\
\hline$V c \times f$ & 3523.38151 & 1 & 3523.38151 & 79.8355089 & 0.0710 & 6.75 \\
\hline$V c \times a p$ & 1233.80281 & 1 & 1233.80281 & 27.9564603 & 0.1190 & 2.36 \\
\hline$f \times a p$ & 227.377813 & 1 & 227.377813 & 5.15210269 & 0.2642 & 0.44 \\
\hline Error & 44.1330125 & 1 & 44.1330125 & & & \\
\hline Total & 52248.4988 & 7 & & & & 100 \\
\hline \multicolumn{4}{|c|}{$\mathrm{SD}=6.64$} & \multicolumn{3}{|l|}{$R^{2}=0.9992$} \\
\hline \multicolumn{4}{|c|}{ Mean $=176.43$} & \multicolumn{3}{|c|}{$R^{2}$ Adjusted $=0.9941$} \\
\hline \multicolumn{4}{|c|}{ Coefficient of variation $=3.77$} & \multicolumn{3}{|c|}{$R^{2}$ Predicted $=0.9459$} \\
\hline \multicolumn{4}{|c|}{ Predicted residual error of sum of squares (PRESS) $=2824.51$} & \multicolumn{3}{|c|}{ Adequate precision $=40.087$} \\
\hline \multicolumn{7}{|c|}{ (b) CC670 } \\
\hline Model & 48196.7536 & 6 & 8032.79226 & 10.2733805 & 0.2344 & \\
\hline$V c$ & 26375.3028 & 1 & 26375.3028 & 33.7321708 & 0.1085 & 54.72 \\
\hline$f$ & 19079.8345 & 1 & 19079.8345 & 24.4017762 & 0.1272 & 39.58 \\
\hline$a p$ & 520.515113 & 1 & 520.515113 & 0.66570249 & 0.5643 & 1.08 \\
\hline$V c \times f$ & 2136.29161 & 1 & 2136.29161 & 2.73216782 & 0.3464 & 4.43 \\
\hline$V c \times a p$ & 1.5400125 & 1 & 1.5400125 & 0.00196957 & 0.9718 & 0.003 \\
\hline$f \times a p$ & 83.2695125 & 1 & 83.2695125 & 0.10649589 & 0.7992 & 0.17 \\
\hline Error & 781.903513 & 1 & 781.903513 & & & \\
\hline Total & 48978.6571 & 7 & & & & 100 \\
\hline \multicolumn{4}{|c|}{$\mathrm{SD}=27.96$} & \multicolumn{3}{|l|}{$R^{2}=0.9840$} \\
\hline \multicolumn{4}{|c|}{ Mean $=186.90$} & \multicolumn{3}{|c|}{$R^{2}$ Adjusted $=0.8883$} \\
\hline \multicolumn{4}{|c|}{ Coefficient of variation $=14.96$} & \multicolumn{3}{|c|}{$R^{2}$ Predicted $=0.0217$} \\
\hline \multicolumn{4}{|c|}{ Predicted residual error of sum of squares (PRESS) $=50041.82$} & \multicolumn{3}{|c|}{ Adequate precision $=8.741$} \\
\hline
\end{tabular}


Table 7. Constraints for optimization of cutting conditions.

\begin{tabular}{|c|c|c|c|c|c|}
\hline \multirow{2}{*}{ Condition } & \multirow{2}{*}{ Goal } & \multicolumn{2}{|c|}{ Lower limit } & \multicolumn{2}{|c|}{ Upper limit } \\
\hline & & CC650 & CC670 & CC650 & CC670 \\
\hline Cutting speed $\left(\mathrm{m} \cdot \mathrm{min}^{-1}\right)$ & Is in rang & \multicolumn{2}{|c|}{90} & \multicolumn{2}{|c|}{180} \\
\hline Feed rate $\left(\mathrm{mm} \cdot \mathrm{rev}^{-1}\right)$ & Is in rang & \multicolumn{2}{|c|}{0.08} & \multicolumn{2}{|c|}{0.16} \\
\hline Depth of cut $(\mathrm{mm})$ & Is in rang & \multicolumn{2}{|c|}{0.25} & \multicolumn{2}{|c|}{0.50} \\
\hline Feed force $(F x: F a)$ & Minimize & 36.17 & 48.23 & 277.69 & 232.86 \\
\hline Thrust force $(F y: F r)$ & Minimize & 71.63 & 109.53 & 363.19 & 432.04 \\
\hline Tangential force $(F z: F t)$ & Minimize & 88.90 & 95.14 & 338.01 & 314.98 \\
\hline
\end{tabular}

\section{Optimization of cutting conditions}

The optimal manufacturing conditions for hard turning of AISI 4140 with the constraints of cutting parametric range is that corresponding to lower values of feed force $(F a: F x)$, thrust force $(F r: F y)$ and tangential force $(F t: F z)$ during the dry turning process. The constraints used during the optimization process are summarized in Table 7 Whereas the optimal solutions are reported in Table 8 in a decreasing desirability level order. This same Table shows the RSM optimization results for feed force, thrust force and tangential force. The optimum cutting parameters were obtained in Table 8 with cutting speed of (90 to 92.42$) \mathrm{m} \cdot \mathrm{min}^{-1}$, feed rate of $0.08 \mathrm{~mm} \cdot \mathrm{rev}^{-1}$ and depth of cut (0.25 to 0.31) for CC650 and CC670 tools respectively The optimization was based on the Least Squares Method, i.e. the derived variables according to the minimum. The statistical software called Design-Expert 8 was used.

Desirability function approach has been used for multiple response factors (Fx:Fa, Fy:Fr and Fz:Ft) optimization. The optimization module searches for a combination of factor levels that simultaneously satisfies the requirements placed on each of the responses and factors in an attempt to establish the appropriate model. During the optimization process the aim was to find the optimal values of machining parameters in order to produce the lowest values of cutting force components. To resolve this type of parameter design problem, an objective function, $F(x)$, is defined as follows:

$$
\begin{aligned}
D F & =\left(\prod_{i=1}^{n} d_{i}^{w}\right)^{\frac{1}{\sum_{j-1}^{n} w_{i}}} \\
F(x) & =-D F
\end{aligned}
$$

where $d_{i}$ is the desirability defined for the $i$ th targeted output and $w_{i}$ is the weighting of $d_{i}$. For various goals of each targeted output, the desirability, $d_{i}$, is defined in different forms. If a goal is to reach a specific value of $T_{i}$, the desirability $d_{i}$ is:

$$
\begin{aligned}
& d i=0 \text { if } \Upsilon_{i} \leqslant L_{o w} \\
& d i=\left[\frac{Y i-L o w_{i}}{T_{i}-L_{i}}\right] \text { if } \operatorname{Low}_{i} \leqslant Y_{i} \leqslant T_{i} \\
& d i=\left[\frac{Y i-H i g h_{i}}{T_{i}-H i g h_{i}}\right] \text { if } T_{i} \leqslant Y_{i} \leqslant H i g h_{i} \\
& d i=0 \text { if } \Upsilon_{i} \geqslant H i g h_{i}
\end{aligned}
$$

For a goal to find a maximum, the desirability is shown as follows:

$$
\begin{aligned}
& d i=0 \text { if } \Upsilon_{i} \leqslant L_{\text {Low }} \\
& d i=\left[\frac{Y i-L_{\text {Low }}}{H i g h_{i}-L_{\text {Low }}}\right] \text { if } \operatorname{Low}_{i} \leqslant Y_{i} \leqslant H i g h_{i} \\
& d i=1 \text { if } \Upsilon_{i} \geqslant H_{i g h}
\end{aligned}
$$

For a goal to search for a minimum, the desirability can be defined by the following formulas:

$$
\begin{aligned}
& d i=1 \quad \text { if } \Upsilon_{i} \leqslant \operatorname{Low}_{i} \\
& d i=\left[\frac{H i g h i_{i}-Y_{i}}{H_{i g h}-\operatorname{Low}_{i}}\right] \text { if } \operatorname{Low}_{i} \leqslant Y_{i} \leqslant H i g h_{i} \\
& d i=0 \text { if } \Upsilon_{i} \geqslant H i g h_{i}
\end{aligned}
$$

where the $Y i$ is the found value of the $i$ th output during optimization processes; the $L_{o w}$ and the High $i$ are, respectively, the minimum and the maximum values of the experimental data for the $i$ th output. In Equation (7), $w_{i}$ is set to one since the $d_{i}$ is equally important in this study. The $D F$ is a combined desirability function, and the objective is to choose an optimal setting that maximizes a combined desirability function $D F$, i.e., minimizes $F(x)$.

\section{Conclusions}

The research work presents the application of RSM models which influences the machining variables of feed force, thrust force and tangential force. The relationship between the factors and the performance measures were modeled by polynomial regression. Three process parameters (cutting speed, feed rate and depth of cut) are considered for the development of the models. The developed RSM models are tested through ANOVA and found to be adequate at $95 \%$ confidence interval. The following conclusions are drawn from the present investigation.

(1) The statistical analysis of the cutting force components indicates that the feed rate and cutting speed are the most significant factors on the cutting force components (Fa:Fx, Fr:Fy and Ft:Fz) with the respective contribution of $(31.09 ; 54.02$ and 39.58$)$ and $44.96 ; 26.27$ and 47.72 )] \% for CC650 insert by against a respective contribution $(22.22 ; 51.07$ and 39.58$)$ and $69.02 ; 39.11$ and 54.72$)$ ) \% for CC670 insert. 
Table 8. Optimization results.

\begin{tabular}{|c|c|c|c|c|c|c|c|}
\hline \multirow{2}{*}{ Test No. } & \multirow{2}{*}{$V c\left(\mathrm{~m} \cdot \min ^{-1}\right)$} & \multirow{2}{*}{$f\left(\mathrm{~mm} \cdot \mathrm{rev}^{-1}\right)$} & \multirow{2}{*}{$a p(\mathrm{~mm})$} & \multicolumn{3}{|c|}{ Cutting force components } & \multirow{2}{*}{ Desirability } \\
\hline & & & & $F a: F x(\mathrm{~N})$ & Fr:Fy $(\mathrm{N})$ & $F t: F z(\mathrm{~N})$ & \\
\hline \multicolumn{8}{|c|}{ CC650 } \\
\hline 1 & 90 & 0.08 & 0.25 & 33.376 & 73.076 & 86.559 & 0.998 \\
\hline 2 & 91.43 & 0.08 & 0.25 & 34.558 & 74.544 & 88.055 & 0.996 \\
\hline 3 & 92.1 & 0.08 & 0.25 & 35.111 & 75.233 & 88.753 & 0.995 \\
\hline 4 & 92.42 & 0.08 & 0.25 & 35.382 & 75.570 & 89.094 & 0.995 \\
\hline 5 & 90 & 0.08 & 0.31 & 36.322 & 78.826 & 88.504 & 0.991 \\
\hline \multicolumn{8}{|c|}{ CC670 } \\
\hline 1 & 90 & 0.08 & 0.4 & 48.229 & 133.380 & 94.280 & 0.974 \\
\hline 2 & 91.67 & 0.08 & 0.42 & 48.220 & 135.938 & 93.978 & 0.971 \\
\hline 3 & 92.79 & 0.08 & 0.44 & 48.218 & 137.593 & 93.733 & 0.970 \\
\hline 4 & 95.63 & 0.08 & 0.45 & 49.783 & 140.420 & 95.140 & 0.964 \\
\hline 5 & 91.63 & 0.08 & 0.33 & 54.530 & 130.611 & 102.336 & 0.955 \\
\hline
\end{tabular}

(2) The statistical models deduced define the degree of influence of each cutting regime element on cutting force components (Fa:Fx, Fr:Fy and Ft:Fz). They can also be used for optimization of the hard cutting process.

(3) The models developed for different forces using regression analysis are also proved good where predicted values of forces are very close to the experimental values and desirability is also very high (96.48-99.98)\%.

(4) The ranges of best cutting conditions adopted, are: cutting speed (90 to 92.42 ) m.min ${ }^{-1}$, feed rate of 0.08 mm.rev ${ }^{-1}$ and depth of cut (0.25 to 0.31) for CC650 and CC670 tools respectively.

(5) In general, ceramic cutting insert CC650 has the better performance compared with ceramic cutting insert CC670, in particular for the cutting force components of the machining. Ratios mean value ( 8 tests) for cutting force components (Fa:Fx, Fr:Fy and Ft:Fz) is of (1.07; 1.4 and 1.05$)$ respectively.

\section{References}

[1] K. Bouacha, M.A. Yallese, T. Mabrouki, J-F. Rigal, Statistical analysis of surface roughness and cutting forces using response surface methodology in hard turning of AISI 52100 bearing steel with CBN tool. Int. J. Refract. Metals Hard Mater. 28 (2010) 349-361

[2] I. Asiltürk, S. Neseli, Multi response optimization of CNC turning parameters via Taguchi method-based response surface analysis, Measurement 45 (2012) 785-794

[3] Z. Hessainia, A. Belbah, M.A. Yallese, T. Mabrouki, J-F. Rigal, On the prediction of surface roughness in the hard turning based on cutting parameters and tool vibrations, Measurement 6 (2013) 1671-1678

[4] B. Fnides, M.A. Yallese, T. Mabrouki, J-F. Rigal, Application of response surface methodology for determining cutting force model in turning hardened AISI H11 hot work tool steel, Sadhana 36 (2011) 109-123

[5] R.C. Dewes, D.K. Aspinwall, A review of ultra high speed milling of hardened steels, J. Mater. Process. Technol. 69 (1997) 1-17

[6] B. Fnides, S. Boutabba, M. Fnides, H. Aouici, M.A. Yallese, Cutting tools flank wear and productivity investigation in straight turning of X38CrMoV5-1 (50 HRC), J. Appl. Eng. Technol. 3 (2013) 1-10
[7] H. Aouici, M.A. Yallese, K. Chaoui, T. Mabrouki, J.-F. Rigal, Analysis of surface roughness and cutting force components in hard turning with CBN tool: Prediction model and cutting conditions optimization, Measurement 45 (2012) 344-353

[8] H. Öktem, T. Erzurumluand H. Kurtaran, Application of response surface methodology in the optimization of cutting conditions for surface roughness, J. Mater. Process. Technol. 170 (2005) 11-16

[9] J.S. Dureja, V.K. Gupta, M. Dogra, Design optimization of cutting conditions and analysis of their effect on tool wear and surface roughness during hard turning of AISI-H11 steel with a coated mixed ceramic tool, J. Eng. Manuf. 223 (2009) 1441-1453

[10] S. Neseli, S. Yaldiz, E. Turkes, Optimization of tool geometry parameters for turning operations based on the response surface methodology, Measurement 44 (2011) $580-587$

[11] H. Aouici, M.A. Yallese, B. Fnides, K. Chaoui, T. Mabrouki, Modeling, optimization of hard turning of X38CrMoV5-1 steel with CBN tool, J. Mech. Sci. Technol. 25 (2011) 2843-2851

[12] M. Elbah, M.A. Yallese, H. Aouici, T. Mabrouki, J.-F. Rigal, Comparative assessment of wiper and conventional ceramic tools on surface roughness in hard turning AISI 4140 steel, Measurement 46 (2013) 3041-3056

[13] D.I. Lalwani, N.K. Mehta, P.K. Jain, Experimental investigations of cutting parameters influence on cutting forces and surface roughness in finish hard turning of MDN250 steel, J. Mater. Process. Technol. 206 (2008) 167-179

[14] J.G. Lima, R.F. Avila, A.M. Abrao, M. Faustino, J.P. Davim. Hard turning AISI 4340 high strength low alloy steel and AISI D2 cold work steel, J. Mater. Process. Technol. 169 (2005) 388-395

[15] C. Fetecau, F. Stan, Study of cutting force and surface roughness in the turning of polytetrafluoroethylene composites with a polycrystalline diamond tool, Measurement 45 (2012) 1367-1379

[16] K. Bouacha, M.A. Yallese, T. Mabrouki, J.F. Rigal, Statistical analysis of surface roughness and cutting forces using response surface methodology in hard turning of AISI 52100 bearing steel with CBN tool, Int. J. Refract. Metals Hard Mater. 28 (2010) 349-361 
[17] R. Suresh, S. Basavarajappa, G.L. Samuel, Some studies on hard turning of AISI 4340 steel using multilayer coated carbide tool, Measurement 45 (2012) 1367-1379

[18] M.W. Azizi, S. Belhadi, M.A. Yallese, T. Mabrouki, J.-F. Rigal, Surface roughness and cutting forces modeling for optimization of machining condition in finish hard turning of AISI 52100 steel, J. Mech. Sci. Technol. 26 (2012) 4105-4114

[19] H. Aouici, M.A. Yallese, A. Belbah, M.F. Ameur, M. Elbah, Experimental investigation of cutting parameters influence on surface roughness and cutting forces in hard turning of X38CrMoV5-1 with CBN tool, Sadhana 38 (2013) 429-445

[20] A. Kumar Sahoo, B. Sahoo, Experimental investigations on machinability aspects in finish hard turning of AISI 4340 steel using uncoated and multilayer coated carbide inserts, Measurement 45 (2012) 2153-2165

[21] M.H. Cetin, B. Ozcelik, E. Kuram, E. Demirban, Evaluation of vegetable based cutting fluids with extreme pressure and cutting parameters in turning of AISI 304L by Taguchi method, J. Clean. Prod. 19 (2011) 2049-2056
[22] S.R. Das, D. Dhupal, A. Kumar, Experimental investigation into machinability of hardened AISI 4140 steel using TiN coated ceramic tool, Measurement, 62 (2015) 108126

[23] V.N. Gaitonde, S.R. Karnik, L. Figueira, J.P. Davim, Machinability investigations in hard turning of AISI D2 cold work tool steel with conventional and wiper ceramic inserts, Int. J. Refract. Metals. Hard Mater. 27 (2009) $754-763$

[24] B. Fnides, Comportement des outils de coupe en tournage dur à sec - Modélisation des paramètres technologiques, Presses Académiques Francophones, 2014, ISBN: 978-38381-7843-1

[25] J.S. Kwak, Application of Taguchi and response surface methodologies for geometric error in surface grinding process, Int. J. Mach. Tools Manuf. 45 (2005) 327-334

[26] C.E. Walker, A.M. Parkhurst, Response surface analysis of bake-lab data with a personal computer, Cereal Foods World 29 (1984) 662 